\title{
REVIEW
}

\section{Pharmacogenetics of warfarin: challenges and opportunities}

\begin{abstract}
Ming Ta Michael Lee $e^{1,2,3}$ and Teri E Klein ${ }^{4}$
Since the introduction in the 1950s, warfarin has become the commonly used oral anticoagulant for the prevention of thromboembolism in patients with deep vein thrombosis, atrial fibrillation or prosthetic heart valve replacement. Warfarin is highly efficacious; however, achieving the desired anticoagulation is difficult because of its narrow therapeutic window and highly variable dose response among individuals. Bleeding is often associated with overdose of warfarin. There is overwhelming evidence that an individual's warfarin maintenance is associated with clinical factors and genetic variations, most notably polymorphisms in cytochrome P450 2C9 and vitamin K epoxide reductase subunit 1. Numerous dose-prediction algorithms incorporating both genetic and clinical factors have been developed and tested clinically. However, results from major clinical trials are not available yet. This review aims to provide an overview of the field of warfarin which includes information about the drug, genetics of warfarin dose requirements, dosing algorithms developed and the challenges for the clinical implementation of warfarin pharmacogenetics.
\end{abstract}

Journal of Human Genetics (2013) 58, 334-338; doi:10.1038/jhg.2013.40; published online 9 May 2013

Keywords: CYP2C9; CYP4F2; pharmacogenetics; VKORC1; warfarin

\section{WARFARIN}

Warfarin, first introduced in the 1950s, has now become the most commonly prescribed oral anticoagulant for the prevention of thromboembolism in patients with deep vein thrombosis, atrial fibrillation or prosthetic heart valve replacement. ${ }^{1-4}$ Over 25 million prescriptions ${ }^{5}$ have been made in the United States with world's total prescriptions reaching $0.5-1.5 \%$ of the population. ${ }^{6}$ Warfarin exists as a racemic mixture of $(\mathrm{R})$ and $(\mathrm{S})$ - enantiomers with the $(\mathrm{S})$ form being more potent than the (R) isomer. ${ }^{7}$ Warfarin exerts its anticoagulation effect by blocking the vitamin $\mathrm{K}$ regeneration cycle. Gamma carboxylation of vitamin K-dependent clotting factors (factor II, VII, IX and X) is essential for blood clotting. Vitamin $\mathrm{K}$ and oxygen are required for the gamma carboxylase to add a carbon dioxide molecule to the side chain of glutamic acid in the clotting factors. During carboxylation, the reduced vitamin $\mathrm{K}$ is oxidized to vitamin $\mathrm{K}$ 2,3-epoxide, from which the reduced vitamin $\mathrm{K}$ is regenerated for another cycle of catalysis. ${ }^{8,9}$ Even though warfarin is highly efficacious, it is plagued by a narrow therapeutic window, and large interindividual variations in the warfarin dosage required for achieving optimal anticoagulation. Variations can range as much as 10-20 fold differences in the dose required to achieve optimal anticoagulation..$^{10}$ In addition, there are also significant ethnic dose differences, Asian populations usually require lower doses relative to Caucasian or African populations. ${ }^{11,12}$

Because of the large difference in the dose required for warfarin, the anticoagulation effect must to be monitored regularly. Anticoagulation status is measured as the International Normalized Ratio (INR), which is a measure of the prothrombin time (PT) consisted of vitamin K-dependent coagulation factors II, VII and X. ${ }^{13}$ The INR is calculated by dividing a patient's PT with mean normal PT, the geometric mean of the PTs of the healthy adult population. A normal individual usually has an INR of 1, and INR of 2 means that the clotting time has doubled. The target INR for warfarin treatment is dependent upon the indication; the most widely accepted range is $2.0-3.0 .^{14}$

It can be difficult to maintain an INR in the target range of 2.0-3.0, and therefore, over- and under-anticoagulation are very common during warfarin treatment. Under-anticoagulation can lead to thrombosis and over-anticoagulation is often associated with bleeding. The most common adverse effect of warfarin is bleeding. ${ }^{15-17}$ In the United States between 2007 and 2009, warfarin-associated adverse events accounted for $33 \%$ of drug-related hospitalizations, ${ }^{18}$ and warfarin has become one of the top 10 drugs for drug-related hospitalization in the United States. Incidence of adverse bleeding is associated with elevated INR. Studies have shown that risk of bleeding is increased when the INR exceeds 4 , and the risk rises sharply with values $>5 .{ }^{19}$ Vitamin $\mathrm{K}$ is the antagonist of warfarin and is used to reverse the effect of warfarin in the event of high INR or bleeding. These challenges led to a significant underuse of warfarin, especially in Asian countries where physicians often fear of bleeding because of lower doses required in the region. One study in Taiwan showed that only $24.7 \%$ of the atrial fibrillation patients received appropriate treatment. ${ }^{20}$

${ }^{1}$ Laboratory for International Alliance, RIKEN Center for Genomic Medicine, Yokohama, Japan; ${ }^{2}$ Institute of Biomedical Sciences, Academia Sinica, Taipei, Taiwan; ${ }^{3}$ Graduate Institute of Chinese Medical Science, China Medical University, Taichung, Taiwan and ${ }^{4}$ Department of Genetics, School of Medicine, Stanford University, Stanford, CA, USA Correspondence: Dr MTM Lee, Laboratory for International Alliance on Genomic Research, RIKEN Center for Integrative Medical Sciences, 1-7-22, Suehiro-cho, Tsurumi-ku, Kanagawa, Yokohama 230-0045, Japan.

E-mail: mikelee@src.riken.jp

Received 25 March 2013; accepted 11 April 2013; published online 9 May 2013 
NONGENETIC FACTORS INFLUENCING WARFARIN RESPONSE Vitamin $\mathrm{K}$ is required for the coagulation cascade and is also the antagonist for warfarin. It has been shown that vitamin $\mathrm{K}$ intake positively correlates with warfarin dose. ${ }^{21}$ Thus, dark green vegetables such as broccoli and spinach rich in Vitamin $\mathrm{K}$ could potentially influence warfarin response. The National Institutes of Health has recommended consistent vitamin $\mathrm{K}$ intake to minimize variations in warfarin response for patients on warfarin treatment. ${ }^{22}$ In addition to dietary interactions, excessive alcohol use can also affect warfarin metabolism and elevate INR. ${ }^{23}$

Several drugs are known to influence warfarin-treatment response. One of the most common concomitant drugs for warfarin treatment is amiodarone. It has been shown that amiodarone decrease the clearance of both (R) and (S) warfarin, ${ }^{24}$ and thus patients should reduce their dose if amiodarone is taken during warfarin treatment. Antibiotics such as metronidazole also reduce the metabolism of warfarin and thus increase the effect of warfarin. Broad-spectrum antibiotics that alter the balance of intestinal flora will enhance the effect of warfarin..$^{25}$ Non-steroidal anti-inflammatory drugs do not directly inhibit or induce warfarin metabolism. However, risk of a warfarin-induced bleed is increased due to non-steroidal antiinflammatory drug-induced gastrointestinal ersosions, even for patients with desired range of INR. ${ }^{25}$ Patients are also at higher risk of hemorrhage if anti-platelets (such as aspirin and clopidogrel) are used. ${ }^{26}$ Drugs that interfere with the vitamin $\mathrm{K}$ cycle (such as acetaminophen whose metabolite inhibits the vitamin $\mathrm{K}$ cycle) can also interfere with warfarin response. ${ }^{27}$

It is well known that there is a positive correlation of age, height and weight with warfarin dose. Recent studies also showed that patients with renal impairments require less warfarin than patients with normal renal function. ${ }^{28}$

\section{GENETIC FACTORS INFLUENCING WARFARIN RESPONSE}

The hunt for genetic determinants influencing warfarin dose began in the 1990s using candidate gene approach. Initial focus was on the warfarin-metabolizing enzyme cytochrome P450 2C9 (CYP2C9), which metabolizes the potent $(\mathrm{S})$ warfarin. ${ }^{29}$ It was soon identified that polymorphisms in CYP2C9 were associated with reduced warfarin dose requirement. ${ }^{30}$ The most common allele is CYP2C9* 1 , which is considered as the wild-type allele. The most common variant in European ancestry are CYP2C9*2 (rs1799853), which has an $\mathrm{Arg}^{144}$ Cys substitution, and CYP2C9*3 (rs1057920), which has an Ile ${ }^{359} \mathrm{Thr}$ substitution. ${ }^{31-33}$ The minor allele of these two variants produces a metabolically impaired enzyme with activities reduced by $30 \%\left(\mathrm{CYP} 2 \mathrm{C}{ }^{*} 2\right)$ and $80 \%(\mathrm{CYP} 2 \mathrm{C} 9 * 3) .{ }^{30}$ The frequency of these variants shows ethnic differences; for example, CYP2C $9^{\star} 2$ is almost absent in some Asian populations, including the Han-Chinese and Japanese populations. Because of the reduced function of these variants, individuals who carry CYP2C $9{ }^{\star} 2$ or ${ }^{\star} 3$ require lower doses of warfarin, especially for those with two copies of the ${ }^{\star} 3$ allele. These individuals are also at greater risk of bleeding during warfarin treatment and require longer time to achieve stable target INR. ${ }^{34,35}$ Additional CYP2C9 variants with reduced metabolic capacity $\left(\mathrm{CYP} 2 \mathrm{C} 9{ }^{\star} 5,{ }^{\star} 6,{ }^{\star} 8\right.$ and $\left.{ }^{\star} 11\right)$ are also identified, and these variants contribute to warfarin dose variation in the African Americans. ${ }^{36-38}$

Metabolizing enzymes for the (R) warfarin, such as CYP1A1 $1^{39}$ and CYP $3 A 5,{ }^{40}$ were also investigated. Because of the minimal effects of (R) warfarin on anticoagulation, they are clinically insignificant. In addition, genes in the warfarin interactive pathways, vitamin $\mathrm{K}$ regeneration cycle and vitamin $\mathrm{K}$-dependent clotting factors were also studied. These genes include CYP2C18, CYP2C19, PROC, ABCB1,
APOE, EPHX1, CALU, GGCX, ORM1, ORM2, factor II, factor V, factor VII, Factor IX and NR112.38,40-56 Unlike CYP2C9, the associations of these genes to warfarin dose variation were limited to some but not all the populations tested, and the effects were too small to have any significant clinical use.

The field of warfarin pharmacogenetics significantly advanced when the second major genetic determinant, vitamin $\mathrm{K}$ epoxide reductase subunit 1 (VKORC1), was identified. ${ }^{57,58}$ VKORC1 is responsible for the regeneration of vitamin $\mathrm{K}$ epoxide to vitamin $\mathrm{K}$ and is the rate-limiting step in the vitamin $\mathrm{K}$ regeneration cycle. ${ }^{48}$ Several single-nucleotide polymorphisms in strong linkage disequilibrium were identified and associated with warfarin dose. ${ }^{59}$ The most commonly used VKORC1 variant is a noncoding variant (VKORC1 - $1639 \mathrm{G}>\mathrm{A}$, rs9923231) which lies in the promoter region of VKORC1. The $-1639 \mathrm{G}$ allele destroys a transcriptionbinding site (E-box) that resulted in increased promoter activity, ${ }^{60}$ and thus, individuals that carry the $G$ allele require higher warfarin doses than those with the A allele. This association was soon confirmed in three major populations (African, Asian and Caucasian), ${ }^{12,61}$ and numerous populations around the world. ${ }^{62-65}$ In addition, several rare nonsynonymous mutations in VKORC1 which confer warfarin resistance were also identified. ${ }^{66}$

To identify additional genes that contribute to variations in warfarin dosing, one study using Affymetrix's DMET (Drug Metabolizing Enzymes and Transporters) gene chip and several genomewide association studies were conducted. ${ }^{67-70}$ In addition to confirming the previously known associations of CYP2C9 and VKORC1 as the major genetic determinants for warfarin dosing variation, these studies also identified CYP4F2 as the additional genetic factor. It was demonstrated that CYP4F2 contributes to vitamin $\mathrm{K} 1$ oxidation and the nonsynonymous polymorphism, resulting in decreased activity. ${ }^{71}$ The association of the CFP4F2 variant (rs2108622) and warfarin dose was subsequently confirmed in a meta-analysis involving more than 9000 participants from 30 studies. $^{72}$ Even though the association of CYP4F2 is significant, the effect size is much lower than those contributed by VKORC1 and CYP2C9, and its clinical use remains to be further studied.

\section{DOSING ALGORITHMS}

Because of the difficulties and the potential lethal side effects of warfarin therapy, efforts were made early on trying to reduce the adverse events. Most of the efforts focused on developing dosing algorithms or computerized programs using clinical variables to guide physicians prescribing warfarin or to predict warfarin dose. ${ }^{73-76}$ However, there was no wide adoption due to the lack of effectiveness of the programs and the low variability $(\sim 20 \%)$ explained by the clinical algorithms. With the identifications of the genetic factors associated with warfarin dosing, efforts were refocused on developing dosing algorithms incorporating both clinical and genetic variables aimed to explain a greater variation in dosing as well as to better predict the maintenance dose. The earliest pharmacogenetic dosing algorithms used just CYP2C9 genotypes. ${ }^{76,77}$ VKORC1 genotypes were quickly added as the second genetic factor soon after its identification. A few recently developed algorithms also included CYP4F2 and other genetic factors. ${ }^{78,79}$ Over 20 dosing algorithms for various ethnic groups have been developed. ${ }^{12,80-82}$ In general, most of these algorithms showed that demographic factors (age, gender, weight and height) and the use of concomitant drugs account for approximately $25 \%$ of the variability in dosage. Genetic factors (CYP2C9 and VKORC1) account for additional $35-50 \%$ of the variability. However, the 
problem for most of these algorithms is that they were developed using a relatively small sample size usually from a single ethnic group. An international group, International Warfarin Pharmacogenetics Consortium (IWPC), was formed to tackle this issue. Clinical and genetic data were collected from over 5000 patients around the world. Two dosing algorithms were developed, one with clinical variables only and the other with both genetic and clinical factors, using information from 4042 individuals, and were then tested and replicated on additional 1009 patients. ${ }^{12}$ The phamacogenetics dosing algorithm outperformed the nongenetic clinical algorithm and fixed dose. The same study also showed that the greatest benefit for pharmacokinetics dosing were patients requiring $<21 \mathrm{mg}$ per week or $>49 \mathrm{mg}$ per week of warfarin; these patients account for $>40 \%$ of the total patients. However, these algorithms, including the IWPC, were developed using mostly adult populations and might not be suitable for children. Several new algorithms using pediatric patients were developed to address this issue. ${ }^{83,84}$ In addition to developing a global dosing algorithm, researchers of IWPC also used the collected information to show that one VKORC1 singlenucleotide polymorphism $(-1639 \mathrm{G}>\mathrm{A})$ is sufficient, and adding other common VKORC1 single-nucleotide polymorphisms or the uses of haplotypes in dosing algorithms does not further improve warfarin dose prediction. ${ }^{61}$

All the algorithms published to date, at best, explain about $80 \%$ of the variations in warfarin dosing. ${ }^{85}$ Novel variants yet to be identified could explain some of the missing variations. It is more likely that the remaining variations cannot be explained by any algorithms. As discussed above, diet is an important factor influencing warfarin. However, it is extremely difficult to account for these variations. Even within the same country/ethnic group, food preference can differ. In addition, interactions between warfarin and herbal medicine are not well documented. All these contribute to the missing variations in the current dosing algorithms.

\section{CLINICAL IMPLEMENTATION OF WARFARIN PHARMACOGENETICS}

Given the enormous evidence supporting the associations of genetic factors with warfarin dose and the regulatory mandate for drug safety, the US Food and Drug Administration (FDA) updated the drug label for warfarin to include information on the impact of genetic variation. However, this update caused controversy and concerns from many physicians, as it did not provide any specific dosing recommendation using genetics. The label was updated again by the FDA to include a genotype-stratified dosing table in 2010. A study was conducted to compare the accuracy of the dosing table and some of the developed genetic dosing algorithms. The study found that the genetic dosing table predicted warfarin dose better than empirical dosing, and the pharmacogenetics dosing algorithms were the most accurate. ${ }^{86}$

The Clinical Pharmacogenetics Implementation Consortium, a partnership of the National Institutes of Health PharmGKB (www.pharmgkb.org) and the Pharmacogenomics Research Network (www.pgrn.org), has developed a guideline to provide recommendation to physicians on the interpretation and use of the CYP2C9 and VKORC1 genotype data should the genotype results be available to the physicians. $^{6}$ This guideline recommends that if genetic information is available, warfarin dosing should be estimated using a pharmacogenetic dosing algorithm. If the use of algorithms is not possible, a genotype dosing table should still be used. As it can be difficult to calculate the warfarin dose using developed algorithms, websites have been setup to assist this. Warfarindosing.org (http:// www.warfarindosing.org) is a free website that includes the IWPC and the Gage algorithms. The PharmGKB database also generated a tool to help estimate warfarin dose using the IWPC algorithm (http:// www.pharmgkb.org/drug/PA451906).

Even though no one disputes the influence of genetics on warfarin dosing, the benefit of clinical use of warfarin pharmacogenetics, such as percent time in therapeutic range, fewer out of range INRs, fewer dose adjustments and reduced incidents of adverse bleeding, is still debated. Several studies of various study design, including randomized trials, have been performed to address these issues. ${ }^{81,87-95}$ Some of the studies showed a real therapeutic advantage by including the genetic information. The Medco-Mayo Warfarin Effectiveness study ${ }^{90}$ showed that $31 \%$ of the patients were less likely to be hospitalized for any cause and $28 \%$ less likely to be hospitalized for a bleeding episode or thromboembolism if the treating physicians were given the VKORC1 and CYP2C9 genotype information. However, the serious limitation of this study is that the genotype data were provided on average, 32 days after the start of treatment. In addition, the sample sizes of these studies were too small to have adequate power to detect the genetic effects.

The first break-through in the clinical pharmacogenetic study of warfarin is the CoumaGen-II study. ${ }^{96}$ It is the first randomized trial with adequate power (504 cases with pharmacogenetic-guided dosing and 1911 controls with standard dosing) to show that patients in the pharmacogenetic-guided dosing arm have higher percentage of patients stayed in the therapeutic INR range, fewer INR $\geqslant 4$ and $\leqslant 1.5$, and less serious adverse events. In addition to CoumaGen-II, several large randomize trials are ongoing to test the benefits of pharmacogenetic-guided dosing. ${ }^{6}$

\section{FUTURE PERSPECTIVE}

The Clinical Pharmacogenetics Implementation Consortium guideline and the clinical trials were designed to remove roadblocks for the clinical implementation of warfarin pharmacogenetics. The clinical trials will provide the evidence required for the clinical use of genetics, and the Clinical Pharmacogenetics Implementation Consortium guideline provides recommended actions on the available genotype data. The last remaining hurdle is in the infrastructure required for fast, reliable and economical genotyping platform. There are currently four genotyping platforms approved by the US FDA: eQ-PCR LC Warfarin Genotyping Kit (TrimGen, Sparks, MD, USA), eSensoe Warfarin Sensitivity test (GenMark Diagnostics, Inc, Carlsbad, CA, USA), Infinity Warfarin Assay (Autogenomics, Inc, Vista, CA, USA) and Verigene Warfarin Metabolism Nucleic Acid Test (Nanosphere, Northbrook, IL, USA). A number of none-FDA-approved tests are also available (http://www.pharmgkb.org/drug/PA451906\#tabview= tab0\&subtab=34). However, these platforms are still not widely available outside of the major medical center setting. It can sometimes take weeks before the results are made available to patients or their physicians. As the use of pharmacogenetic-guided dosing is most likely to benefit the patients during the initiation stage, it is vital that the patients get the genotype data before treatment.

Because of the difficulties associated with warfarin use and the importance of anticoagulation treatment, pharmaceutical companies have been developing a new generation of oral anticoagulants, and several new anticoagulants have emerged from the horizon. Both direct thrombin inhibitor (dabigatran) ${ }^{97}$ and factor Xa inhibitor (rivoxaban) $)^{98}$ have recently obtained FDA approval. Studies have shown that these new anticoagulants are non-inferior, and in some cases superior, to warfarin. However, the time in treatment range is low, raising some doubt on the performance on the new drugs. These new anticoagulants still have several issues preventing them for wide 
adoption. First, these new drugs can still cause adverse bleeding, but there is currently no monitoring tests available similar to INR for warfarin that can monitor the anticoagulation status. Thus, there is no way to identify patients who are at high risk for bleeding. Second, the cost associated with these new anticoagulants is much higher. One study using patients with atrial fibrillation concluded that it is costeffective to use dabigatran in patients with poor INR control, whereas warfarin is more cost-effective in patients with good INR control. ${ }^{99}$ Lastly, patients on the new anticoagulants are at greater risk when adverse bleeding occurs, as there is no antidote to reverse the effect.

With over 60 years of use, there is enormous data on the safety, clinical use and genetics for warfarin. Thus, at least in the short term, warfarin still will be the most prescribed oral anticoagulants. The results of the ongoing clinical trials may decide the future of warfarin. If the trials show conclusively the benefit of using pharmacogenetics in guiding warfarin use, with the rapid decrease in the cost of genotyping, warfarin may still be a competent oral anticoagulant.

\section{ACKNOWLEDGEMENTS}

Supported by grants from the NIH/NIGMS R24 GM61374 (TEK).

1 Hirsh, J. Antithrombotic therapy in deep vein thrombosis and pulmonary embolism. Am. Heart J. 123, 1115-1122 (1992)

2 Hirsh, J., Dalen, J., Anderson, D. R., Poller, L., Bussey, H., Ansell, J. et al. Oral anticoagulants: mechanism of action, clinical effectiveness, and optimal therapeutic range. Chest 119, 8S-21S (2001).

3 Laupacis, A., Albers, G., Dalen, J., Dunn, M., Feinberg, W. \& Jacobson, A. Antithrombotic therapy in atrial fibrillation. Chest 108, 352S-359S (1995).

4 Stein, P. D., Alpert, J. S., Copeland, J., Dalen, J. E., Goldman, S. \& Turpie, A. G. Antithrombotic therapy in patients with mechanical and biological prosthetic heart valves. Chest 108, 371S-379S (1995).

5 FDA Drug Safety Communication: Safety review of post-market reports of serious bleeding events with the anticoagulant Pradaxa (dabigatran etexilate mesylate). (e-pub ahead of print 7 December 2011; http://www.fda.gov/drugs/drugsafety/ ucm282724.htm)

6 Johnson, J. A., Gong, L., Whirl-Carrillo, M., Gage, B. F., Scott, S. A., Stein, C. M. et al Clinical Pharmacogenetics Implementation Consortium Guidelines for CYP2C9 and VKORC1 genotypes and warfarin dosing. Clin. Pharmacol. Ther. 90, 625-629 (2011).

7 Wittkowsky, A. K. Warfarin and other coumarin derivatives: pharmacokinetics, pharmacodynamics, and drug interactions. Semin. Vasc. Med. 3, 221-230 (2003).

8 Bell, R. G. \& Matschiner, J. T. Warfarin and the inhibition of vitamin K activity by an oxide metabolite. Nature 237, 32-33 (1972)

9 Wallin, R. \& Martin, L. F. Vitamin K-dependent carboxylation and vitamin K metabolism in liver. Effects of warfarin. J. Clin. Invest. 76, 1879-1884 (1985).

10 Loebstein, R., Yonath, H., Peleg, D., Almog, S., Rotenberg, M., Lubetsky, A. et al. Interindividual variability in sensitivity to warfarin-nature or nurture? Clin. Pharmacol. Ther. 70, 159-164 (2001).

11 Takahashi, H., Wilkinson, G. R., Caraco, Y., Muszkat, M., Kim, R. B., Kashima, T. et al. Population differences in S-warfarin metabolism between CYP2C9 genotype-matched Caucasian and Japanese patients. Clin. Pharmacol. Ther. 73, 253-263 (2003).

12 Klein, T. E., Altman, R. B., Eriksson, N., Gage, B. F., Kimmel, S. E., Lee, M. T. et al. Estimation of the warfarin dose with clinical and pharmacogenetic data. N. Engl. J. Med. 360, 753-764 (2009).

13 van den Besselaar, A. M., Poller, L. \& Tripodi, A. Definition of the International Normalized Ratio (INR) and its consequences for the calibration procedure of thromboplastin preparations: a rebuttal. J. Thromb. Haemost. 2, 1490-1491, reply 1492-1494 (2004)

14 Keeling, D., Baglin, T., Tait, C., Watson, H., Perry, D., Baglin, C. et al. Guidelines on oral anticoagulation with warfarin-fourth edition. Br. J. Haematol. 154, 311-324 (2011).

15 Bogousslavsky, J. \& Regli, F. Anticoagulant-induced intracerebral bleeding in brain ischemia. Evaluation in 200 patients with TIAs, emboli from the heart, and progressing stroke. Acta Neurol. Scand. 71, 464-471 (1985)

16 Gullov, A. L., Koefoed, B. G. \& Petersen, P. Bleeding complications to long-term oral anticoagulant therapy. J. Thromb. Thrombolysis 1, 17-25 (1994).

17 Landefeld, C. S. \& Beyth, R. J. Anticoagulant-related bleeding: clinical epidemiology, prediction, and prevention. Am. J. Med. 95, 315-328 (1993).

18 Budnitz, D. S., Lovegrove, M. C., Shehab, N. \& Richards, C. L. Emergency hospitalizations for adverse drug events in older Americans. N. Engl. J. Med. 365, 2002-2012 (2011).

19 Hirsh, J., Fuster, V., Ansell, J. \& Halperin, J. L. American Heart Association/American College of Cardiology F. American Heart Association/American College of Cardiology Foundation guide to warfarin therapy. J. Am. Coll. Cardiol. 41, 1633-1652 (2003).
20 Lin, L. J., Cheng, M. H., Lee, C. H., Wung, D. C., Cheng, C. L. \& Kao Yang, Y. H. Compliance with antithrombotic prescribing guidelines for patients with atrial fibrillation-a nationwide descriptive study in Taiwan. Clin. Ther. 30, 1726-1736 (2008).

21 Rasmussen, M. A., Skov, J., Bladbjerg, E. M., Sidelmann, J. J., Vamosi, M. \& Jespersen, J. Multivariate analysis of the relation between diet and warfarin dose. Eur. J. Clin. Pharmacol. 68, 321-328 (2012).

22 Important information to know when you are taking: warfarin (coumadin) and vitamin k. (e-pub ahead of print 5 September 2012; http://www.cc.nih.gov/ccc/patient_education/drug nutrient/coumadin1.pdf)

23 Weathermon, R. \& Crabb, D. W. Alcohol and medication interactions. Alcohol Res. Health 23, 40-54 (1999).

24 Heimark, L. D., Wienkers, L., Kunze, K., Gibaldi, M., Eddy, A. C., Trager, W. F. et al. The mechanism of the interaction between amiodarone and warfarin in humans. Clin. Pharmacol. Ther. 51, 398-407 (1992).

25 Juurlink, D. N. Drug interactions with warfarin: what clinicians need to know. CMAJ 177, 369-371 (2007)

26 Suh, D. C., Nelson, W. W., Choi, J. C. \& Choi, I. Risk of hemorrhage and treatment costs associated with warfarin drug interactions in patients with atrial fibrillation. Clin. Ther. 34, 1569-1582 (2012).

27 Thijssen, H. H., Soute, B. A., Vervoort, L. M. \& Claessens, J. G. Paracetamol (acetaminophen) warfarin interaction: NAPQI, the toxic metabolite of paracetamol, is an inhibitor of enzymes in the vitamin K cycle. Thromb. Haemost. 92, 797-802 (2004).

28 Limdi, N. A., Limdi, M. A., Cavallari, L., Anderson, A. M., Crowley, M. R., Baird, M. F. et al. Warfarin dosing in patients with impaired kidney function. Am. J. Kidney Dis 56, 823-831 (2010).

29 Rettie, A. E., Korzekwa, K. R., Kunze, K. L., Lawrence, R. F., Eddy, A. C., Aoyama, T. et al. Hydroxylation of warfarin by human cDNA-expressed cytochrome P-450: a role for P-4502C9 in the etiology of (S)-warfarin-drug interactions. Chem. Res. Toxicol. 5, 54-59 (1992).

30 Furuya, H., Fernandez-Salguero, P., Gregory, W., Taber, H., Steward, A., Gonzalez, F. J. et al. Genetic polymorphism of CYP2C9 and its effect on warfarin maintenance dose requirement in patients undergoing anticoagulation therapy. Pharmacogenetics 5, 389-392 (1995).

31 Takahashi, H. \& Echizen, H. Pharmacogenetics of CYP2C9 and interindividual variability in anticoagulant response to warfarin. Pharmacogenomics J. 3, 202-214 (2003).

32 Bhasker, C. R., Miners, J. O., Coulter, S. \& Birkett, D. J. Allelic and functional variability of cytochrome P4502C9. Pharmacogenetics 7, 51-58 (1997).

33 Sullivan-Klose, T. H., Ghanayem, B. I., Bell, D. A., Zhang, Z. Y., Kaminsky, L. S., Shenfield, G. M. et al. The role of the CYP2C9-Leu359 allelic variant in the tolbutamide polymorphism. Pharmacogenetics 6, 341-349 (1996).

34 Aithal, G. P., Day, C. P., Kesteven, P. J. \& Daly, A. K. Association of polymorphisms in the cytochrome P450 CYP2C9 with warfarin dose requirement and risk of bleeding complications. Lancet 353, 717-719 (1999)

35 Lindh, J. D., Holm, L., Andersson, M. L. \& Rane, A. Influence of CYP2C9 genotype on warfarin dose requirements-a systematic review and meta-analysis. Eur. J. Clin. Pharmacol. 65, 365-375 (2009).

36 Scott, S. A., Jaremko, M., Lubitz, S. A., Kornreich, R., Halperin, J. L. \& Desnick, R. J. CYP2C9*8 is prevalent among African-Americans: implications for pharmacogenetic dosing. Pharmacogenomics 10, 1243-1255 (2009).

37 Limdi, N., Goldstein, J., Blaisdell, J., Beasley, T., Rivers, C. \& Acton, R. Influence of CYP2C9 Genotype on warfarin dose among African American and European Americans. Personalized Med. 4, 157-169 (2007).

38 Cavallari, L. H., Langaee, T. Y., Momary, K. M., Shapiro, N. L., Nutescu, E. A., Coty, W. A. et al. Genetic and clinical predictors of warfarin dose requirements in African Americans. Clin. Pharmacol. Ther. 87, 459-464 (2010).

39 Kaminsky, L. S. \& Zhang, Z. Y. Human P450 metabolism of warfarin. Pharmacol. Ther. 73, 67-74 (1997)

40 Wadelius, M., Sorlin, K., Wallerman, O., Karlsson, J., Yue, Q. Y., Magnusson, P. K. et al. Warfarin sensitivity related to CYP2C9, CYP3A5, ABCB1 (MDR1) and other factors. Pharmacogenomics J. 4, 40-48 (2004).

41 Wadelius, M., Chen, L. Y., Downes, K., Ghori, J., Hunt, S., Eriksson, N. et al. Common VKORC1 and GGCX polymorphisms associated with warfarin dose. Pharmacogenomics J. 5, 262-270 (2005).

42 Cha, P. C., Mushiroda, T., Takahashi, A., Saito, S., Shimomura, H., Suzuki, T. et al. High-resolution SNP and haplotype maps of the human gamma-glutamyl carboxylase gene (GGCX) and association study between polymorphisms in GGCX and the warfarin maintenance dose requirement of the Japanese population. J. Hum. Genet. 52, 856-864 (2007).

43 Lee, M. T., Chen, C. H., Chou, C. H., Lu, L. S., Chuang, H. P., Chen, Y. T. et al. Genetic determinants of warfarin dosing in the Han-Chinese population. Pharmacogenomics 10, 1905-1913 (2009).

44 Shikata, E., Ieiri, I., Ishiguro, S., Aono, H., Inoue, K., Koide, T. et al. Association of pharmacokinetic (CYP2C9) and pharmacodynamic (factors II, VII, IX, and X; proteins S and $\mathrm{C}$; and gamma-glutamyl carboxylase) gene variants with warfarin sensitivity. Blood 103, 2630-2635 (2004).

45 Chen, L. Y., Eriksson, N., Gwilliam, R., Bentley, D., Deloukas, P. \& Wadelius, M. Gamma-glutamyl carboxylase (GGCX) microsatellite and warfarin dosing. Blood 106, 3673-3674 (2005).

46 Cain, D., Hutson, S. M. \& Wallin, R. Assembly of the warfarin-sensitive vitamin K 2,3 epoxide reductase enzyme complex in the endoplasmic reticulum membrane. J. Biol. Chem. 272, 29068-29075 (1997). 
47 Loebstein, R., Vecsler, M., Kurnik, D., Austerweil, N., Gak, E., Halkin, H. et al. Common genetic variants of microsomal epoxide hydrolase affect warfarin dose requirements beyond the effect of cytochrome P450 2C9. Clin. Pharmacol. Ther. 77, 365-372 (2005)

48 Wajih, N., Sane, D. C., Hutson, S. M. \& Wallin, R. The inhibitory effect of calumenin on the vitamin K-dependent gamma-carboxylation system. Characterization of the system in normal and warfarin-resistant rats. J. Biol. Chem. 279, 25276-25283 (2004).

49 Kimura, R., Miyashita, K., Kokubo, Y., Akaiwa, Y., Otsubo, R., Nagatsuka, K. et al. Genotypes of vitamin K epoxide reductase, gamma-glutamyl carboxylase, and cytochrome P450 2C9 as determinants of daily warfarin dose in Japanese patients. Thromb. Res. 120, 181-186 (2007).

50 Lin, P. J., Jin, D. Y., Tie, J. K., Presnell, S. R., Straight, D. L. \& Stafford, D. W. The putative vitamin K-dependent gamma-glutamyl carboxylase internal propeptide appears to be the propeptide binding site. J. Biol. Chem. 277, 28584-28591 (2002).

51 Presnell, S. R., Tripathy, A., Lentz, B. R., Jin, D. Y. \& Stafford, D. W. A nove fluorescence assay to study propeptide interaction with gamma-glutamyl carboxylase. Biochemistry 40, 11723-11733 (2001).

52 Rieder, M. J., Reiner, A. P. \& Rettie, A. E. Gamma-glutamyl carboxylase (GGCX) tagSNPs have limited utility for predicting warfarin maintenance dose. J. Thromb. Haemost. 5, 2227-2234 (2007).

53 Saupe, J., Shearer, M. J. \& Kohlmeier, M. Phylloquinone transport and its influence on gamma-carboxyglutamate residues of osteocalcin in patients on maintenance hemodialysis. Am. J. Clin. Nutr. 58, 204-208 (1993).

54 Berkner, K. L. \& Runge, K. W. The physiology of vitamin K nutriture and vitamin K-dependent protein function in atherosclerosis. J. Thromb. Haemost. 2, 2118-2132 (2004).

55 Lal, S., Sandanaraj, E., Jada, S. R., Kong, M. C., Lee, L. H., Goh, B. C. et al. Influence of APOE genotypes and VKORC1 haplotypes on warfarin dose requirements in Asian patients. Br. J. Clin. Pharmacol. 65, 260-264 (2008).

56 Otagiri, M., Maruyama, T., Imai, T., Suenaga, A. \& Imamura, Y. A comparative study of the interaction of warfarin with human alpha 1 -acid glycoprotein and human albumin. J. Pharm. Pharmacol. 39, 416-420 (1987).

57 Li, T., Chang, C. Y., Jin, D. Y., Lin, P. J., Khvorova, A. \& Stafford, D. W. Identification of the gene for vitamin $\mathrm{K}$ epoxide reductase. Nature 427, 541-544 (2004).

58 Rost, S., Fregin, A., Ivaskevicius, V., Conzelmann, E., Hortnagel, K., Pelz, H. J. et al. Mutations in VKORC1 cause warfarin resistance and multiple coagulation factor deficiency type 2. Nature 427, 537-541 (2004)

59 Rieder, M. J., Reiner, A. P., Gage, B. F., Nickerson, D. A., Eby, C. S., McLeod, H. L. et al. Effect of VKORC1 haplotypes on transcriptional regulation and warfarin dose. $N$. Engl. J. Med. 352, 2285-2293 (2005).

60 Yuan, H. Y., Chen, J. J., Lee, M. T., Wung, J. C., Chen, Y. F., Charng, M. J. et al. A novel functional VKORC1 promoter polymorphism is associated with inter-individual and inter-ethnic differences in warfarin sensitivity. Hum. Mol. Genet. 14, 1745-1751 (2005).

61 Limdi, N. A., Wadelius, M., Cavallari, L., Eriksson, N., Crawford, D. C., Lee, M. T. et al. Warfarin pharmacogenetics: a single VKORC1 polymorphism is predictive of dose across 3 racial groups. Blood 115, 3827-3834 (2010).

62 Perini, J. A., Struchiner, C. J., Silva-Assuncao, E., Santana, I. S., Rangel, F., Ojopi, E. B. et al. Pharmacogenetics of warfarin: development of a dosing algorithm for brazilian patients. Clin. Pharmacol. Ther. 84, 722-728 (2008).

63 Djaffar-Jureidini, I., Chamseddine, N., Keleshian, S., Naoufal, R., Zahed, L. \& Hakime, N. Pharmacogenetics of coumarin dosing: prevalence of CYP2C9 and VKORC1 polymorphisms in the Lebanese population. Genet. Test. Mol Biomarkers 15, 827-830 (2011)

64 Pathare, A., Al Khabori, M., Alkindi, S., Al Zadjali, S., Misquith, R., Khan, H. et al. Warfarin pharmacogenetics: development of a dosing algorithm for Omani patients. J. Hum. Genet. 57, 665-669 (2012).

65 Suriapranata, I. M., Tjong, W. Y., Wang, T., Utama, A., Raharjo, S. B., Yuniadi, Y. et al. Genetic factors associated with patient-specific warfarin dose in ethnic Indonesians. BMC Med. Genet. 12, 80 (2011)

66 Scott, S. A., Edelmann, L., Kornreich, R. \& Desnick, R. J. Warfarin pharmacogenetics CYP2C9 and VKORC1 genotypes predict different sensitivity and resistance frequencies in the Ashkenazi and Sephardi Jewish populations. Am. J. Hum. Genet. 82, 495-500 (2008)

67 Cooper, G. M., Johnson, J. A., Langaee, T. Y., Feng, H., Stanaway, I. B., Schwarz, U. I. et al. A genome-wide scan for common genetic variants with a large influence on warfarin maintenance dose. Blood 112, 1022-1027 (2008)

68 Takeuchi, F., McGinnis, R., Bourgeois, S., Barnes, C., Eriksson, N., Soranzo, N. et al. A genome-wide association study confirms VKORC1, CYP2C9, and CYP4F2 as principal genetic determinants of warfarin dose. PLoS Genet. 5, e1000433 (2009).

69 Cha, P. C., Mushiroda, T., Takahashi, A., Kubo, M., Minami, S., Kamatani, N. et al. Genome-wide association study identifies genetic determinants of warfarin responsiveness for Japanese. Hum. Mol. Genet. 19, 4735-4744 (2010).

70 Caldwell, M. D., Awad, T., Johnson, J. A., Gage, B. F., Falkowski, M., Gardina, P. et al. CYP4F2 genetic variant alters required warfarin dose. Blood 111, 4106-4112 (2008).

71 McDonald, M. G., Rieder, M. J., Nakano, M., Hsia, C. K. \& Rettie, A. E. CYP4F2 is a vitamin $\mathrm{K} 1$ oxidase: An explanation for altered warfarin dose in carriers of the V433M variant. Mol. Pharmacol. 75, 1337-1346 (2009).

72 Danese, E., Montagnana, M., Johnson, J. A., Rettie, A. E., Zambon, C. F., Lubitz, S. A. et al. Impact of the CYP4F2 p.V433M polymorphism on coumarin dose requirement: systematic review and meta-analysis. Clin. Pharmacol. Ther. 92, 746-756 (2012).

73 Poller, L., Wright, D. \& Rowlands, M. Prospective comparative study of computer programs used for management of warfarin. J. Clin. Pathol. 46, 299-303 (1993).
74 Vadher, B. D., Patterson, D. L. \& Leaning, M. S. Validation of an algorithm for oral anticoagulant dosing and appointment scheduling. Clin. Lab. Haematol. 17, 339-345 (1995).

75 Ageno, W., Johnson, J., Nowacki, B. \& Turpie, A. G. A computer generated induction system for hospitalized patients starting on oral anticoagulant therapy. Thromb. Haemost. 83, 849-852 (2000).

76 Gage, B. F., Eby, C., Milligan, P. E., Banet, G. A., Duncan, J. R. \& McLeod, H. L. Use of pharmacogenetics and clinical factors to predict the maintenance dose of warfarin. Thromb. Haemost. 91, 87-94 (2004).

77 Kamali, F., Khan, T. I., King, B. P. Frearson, R., Kesteven, P., Wood, P. et al. Contribution of age, body size, and CYP2C9 genotype to anticoagulant response to warfarin. Clin. Pharmacol. Ther. 75, 204-212 (2004).

78 Wei, M., Ye, F., Xie, D., Zhu, Y., Zhu, J., Tao, Y. et al. A new algorithm to predict warfarin dose from polymorphisms of CYP4F2, CYP2C9 and VKORC1 and clinical variables: derivation in Han Chinese patients with non valvular atrial fibrillation. Thromb. Haemost. 107, 1083-1091 (2012)

79 Carcas, A. J., Borobia, A. M., Velasco, M., Abad-Santos, F., Diaz, M. Q., FernandezCapitan, C. et al. Efficiency and effectiveness of the use of an acenocoumaro pharmacogenetic dosing algorithm versus usual care in patients with venous thromboembolic disease initiating oral anticoagulation: study protocol for a randomized controlled trial. Trials 13, 239 (2012).

80 Lubitz, S. A., Scott, S. A., Rothlauf, E. B., Agarwal, A., Peter, I., Doheny, D. et al. Comparative performance of gene-based warfarin dosing algorithms in a multiethnic population. J. Thromb. Haemost. 8, 1018-1026 (2010).

81 Wen, M. S., Lee, M., Chen, J. J., Chuang, H. P., Lu, L. S., Chen, C. H. et al. Prospective study of warfarin dosage requirements based on CYP2C9 and VKORC1 genotypes. Clin. Pharmacol. Ther. 84, 83-89 (2008).

82 Choi, J. R., Kim, J. O., Kang, D. R., Yoon, S. A., Shin, J. Y., Zhang, X. et al. Proposal of pharmacogenetics-based warfarin dosing algorithm in Korean patients. J. Hum. Genet. 56, 290-295 (2011).

83 Biss, T. T., Avery, P. J., Brandao, L. R., Chalmers, E. A., Williams, M. D., Grainger, J. D. et al. VKORC1 and CYP2C9 genotype and patient characteristics explain a large proportion of the variability in warfarin dose requirement among children. Blood 119, 868-873 (2012)

84 Moreau, C., Bajolle, F., Siguret, V., Lasne, D., Golmard, J. L., Elie, C. et al. Vitamin K antagonists in children with heart disease: height and VKORC1 genotype are the main determinants of the warfarin dose requirement. Blood 119, 861-867 (2012).

85 Millican, E., Jacobsen-Lenzini, P. A., Milligan, P. E., Grosso, L., Eby, C., Deych, E. et al. Genetic-based dosing in orthopaedic patients beginning warfarin therapy. Blood 110, 1511-1515 (2007).

86 Finkelman, B. S., Gage, B. F., Johnson, J. A., Brensinger, C. M. \& Kimmel, S. E. Genetic warfarin dosing: tables versus algorithms. J. Am. Coll. Cardiol. 57, 612-618 (2011).

87 Anderson, J. L., Horne, B. D., Stevens, S. M., Grove, A. S., Barton, S., Nicholas, Z. P. et al. Randomized trial of genotype-guided versus standard warfarin dosing in patients initiating oral anticoagulation. Circulation 116, 2563-2570 (2007).

88 Burmester, J. K., Berg, R. L., Yale, S. H., Rottscheit, C. M., Glurich, I. E., Schmelzer, J. R. et al. A randomized controlled trial of genotype-based coumadin initiation. Genet. Med. 13, 509-518 (2011).

89 Caraco, Y., Blotnick, S. \& Muszkat, M. CYP2C9 genotype-guided warfarin prescribing enhances the efficacy and safety of anticoagulation: a prospective randomized controlled study. Clin. Pharmacol. Ther. 83, 460-470 (2008).

90 Epstein, R. S., Moyer, T. P., Aubert, R. E., O Kane, D. J., Xia, F., Verbrugge, R. R. et al. Warfarin genotyping reduces hospitalization rates results from the MM-WES (MedcoMayo Warfarin Effectiveness study). J. Am. Coll. Cardiol. 55, 2804-2812 (2010).

91 Gong, I. Y., Tirona, R. G., Schwarz, U. I., Crown, N., Dresser, G. K., Larue, S. et al. Prospective evaluation of a pharmacogenetics-guided warfarin loading and maintenance dose regimen for initiation of therapy. Blood 118, 3163-3171 (2011).

92 McMillin, G. A., Melis, R., Wilson, A., Strong, M. B., Wanner, N. A., Vinik, R. G. et al. Gene-based warfarin dosing compared with standard of care practices in an orthopedic surgery population: a prospective, parallel cohort study. Ther. Drug. Monit. 32, 338-345 (2010)

93 Carlquist, J. F., Horne, B. D., Muhlestein, J. B., Lappe, D. L., Whiting, B. M., Kolek, M. J. et al. Genotypes of the cytochrome p450 isoform, CYP2C9, and the vitamin K epoxide reductase complex subunit 1 conjointly determine stable warfarin dose: a prospective study. J. Thromb. Thrombolysis 22, 191-197 (2006).

94 Lenzini, P. A., Grice, G. R., Milligan, P. E., Dowd, M. B., Subherwal, S., Deych, E. et al. Laboratory and clinical outcomes of pharmacogenetic vs. clinical protocols for warfarin initiation in orthopedic patients. J. Thromb. Haemost. 6, 1655-1662 (2008).

95 Voora, D., Eby, C., Linder, M. W., Milligan, P. E., Bukaveckas, B. L., McLeod, H. L. et al. Prospective dosing of warfarin based on cytochrome P-450 2 C9 genotype. Thromb. Haemost. 93, 700-705 (2005).

96 Anderson, J. L., Horne, B. D., Stevens, S. M., Woller, S. C., Samuelson, K. M., Mansfield, J. W. et al. A randomized and clinical effectiveness trial comparing two pharmacogenetic algorithms and standard care for individualizing warfarin dosing (CoumaGen-II). Circulation 125, 1997-2005 (2012).

97 Connolly, S. J., Ezekowitz, M. D., Yusuf, S., Eikelboom, J., Oldgren, J., Parekh, A. et al. Dabigatran versus warfarin in patients with atrial fibrillation. N. Engl. J. Med. 361 1139-1151 (2009).

98 Patel, M. R., Mahaffey, K. W., Garg, J., Pan, G., Singer, D. E., Hacke, W. et al. Rivaroxaban versus warfarin in nonvalvular atrial fibrillation. N. Engl. J. Med. 365, 883-891 (2011)

99 Shah, S. V. \& Gage, B. F. Cost-effectiveness of dabigatran for stroke prophylaxis in atrial fibrillation. Circulation 123, 2562-2570 (2011). 